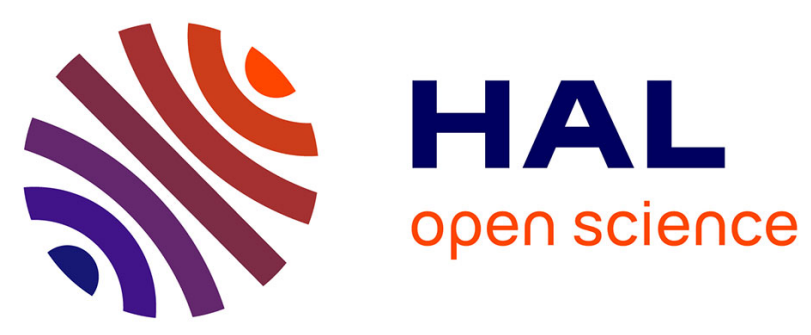

\title{
Imaging gas and plasma interactions in the surface-chemical modification of polymers using micro-plasma jets
}

Jun-Seok Oh, Olumuyiwa T Olabanji, Craig Hale, Raffaello Mariani, Konstantinos Kontis, James W Bradley

\section{To cite this version:}

Jun-Seok Oh, Olumuyiwa T Olabanji, Craig Hale, Raffaello Mariani, Konstantinos Kontis, et al.. Imaging gas and plasma interactions in the surface-chemical modification of polymers using microplasma jets. Journal of Physics D: Applied Physics, 2011, 44 (15), pp.155206. 10.1088/00223727/44/15/155206 . hal-00613264

\section{HAL Id: hal-00613264 \\ https://hal.science/hal-00613264}

Submitted on 4 Aug 2011

HAL is a multi-disciplinary open access archive for the deposit and dissemination of scientific research documents, whether they are published or not. The documents may come from teaching and research institutions in France or abroad, or from public or private research centers.
L'archive ouverte pluridisciplinaire HAL, est destinée au dépôt et à la diffusion de documents scientifiques de niveau recherche, publiés ou non, émanant des établissements d'enseignement et de recherche français ou étrangers, des laboratoires publics ou privés. 
1 Imaging gas and plasma interactions in the surface-chemical modification of polymers

4 Jun-Seok $\mathrm{Oh}^{\text {a) }}$, Olumuyiwa T. Olabanji ${ }^{\text {a) }}$, Craig Hale ${ }^{\text {b) }}$, Raffaello Mariani ${ }^{\text {b) }}$, Konstantinos

5 Kontis $^{\text {b) }}$, James W. Bradley ${ }^{\text {a),c) }}$

6

\section{using micro-plasma jets}

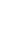

${ }^{a)}$ Department of Electrical Engineering and Electronics, University of Liverpool, L69 3GJ, Liverpool, UK

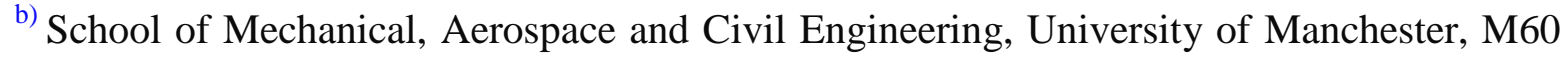
1QD, Manchester, UK

c) Author for correspondence: j.w.bradley@liv.ac.uk

\section{Abstract}

This paper reports on the correlation between gas flow and plasma behaviour in the outflow of a micro-atmospheric pressure plasma jet ( $\mu$-APPJ: capillary $1 \mathrm{~mm}$ and operating in helium) using both 2-D optical imaging and Schlieren photography. Schlieren photography shows that the helium outflow changes from laminar to turbulent conditions after distances between 20 and $50 \mathrm{~mm}$ from nozzle. Above a flow rate of $1.4 \mathrm{slm}$, the length of the laminar region decreases with increasing flow rate. However, by contrast the visible plasma plume increases in length with increasing flow rate until its extension just exceeds that of the laminar region. At this point the plasma becomes turbulent and its length decreases. Exposing polystyrene samples to the plasma jet significantly alters the water contact angle in a defined area, with the hydrophobic polystyrene surface becoming more hydrophilic. This modification occurs both with and without direct contact of the visible glow on the surface. The radius of the treated area is much larger than the width of the visible jet but much smaller than the area of the turbulence on the surface. The treated area reduces with increasing nozzle-substrate distance. 


\section{Introduction}

Non-thermal atmospheric pressure plasmas jets (APPJs) are rapidly gaining importance as tools for plasma processing since they are technologically simple, environmentally friendly and are very economical; they often do not require expensive vacuum equipments and high purity gases [1][2][3][4][5][6]. The applications of APPJs now include deposition [7], surface modification[8][9], sterilization[10][11], and wound treatment [10], particularly important in biomedicine. In all these applications the common feature is the localised process, achievable by the inherent small size of the jet.

Our interests are to use APPJ to modify polymeric surfaces in biomedical research applications, specifically to introduce chosen functional groups onto the surface, and to understand of mechanisms based on the gaseous fluid flow. In some applications, the APPJ lateral extension must necessarily be small ( $50 \mu \mathrm{m}$ internal diameter, ID), for instance to produce micro-patterns without mask for protein and mammalian cell adhesion and binding. Surface modification studies with narrow APPJ's have been reported recently by Szili [8] and Oh [9], with the successful treatment of polystyrene (PS) using capillaries of ID $700 \mu \mathrm{m}$ and $280 \mu \mathrm{m}$ for jets operating in neon and helium respectively. However, the results showed the area of treatment greatly exceed the cross-sectional area of the visible jet with effective radii of treatment being about $10 \mathrm{~mm}$. In fact, it was observed that the entire sample surface $(20 \times$ $20 \mathrm{~mm}$ ) was modified, if only weakly at the edges. The cause of the surface treatment, whether ionic, electronic, neutral, radical or photonic has only been speculated [4], and it is clear from the results in [8] and [9] that treatment occurs on much larger scale lengths than both the capillary and plasma widths. Therefore, to be able design, develop and control $\mu$ APPJ for such small-area treatment we need a better understanding of nature and extent of both the plasma and gas-surface interactions.

In this paper, we report on the correlation between plasma and gas flow scale-lengths and their relationship to the scale of surface treatment on test polystyrene (PS) samples. To do this, we use a 2-D imaging system, equipped with an ICCD camera to view the broad band optical emission and Schlieren photography to observe the (invisible) gas flow dynamics. To 
1 determine the spatial extent of the effect of the jet effluent on the PS surfaces, radial scanning

2 water contact angle (WCA) measurements have been made after treatment.

\section{Experimental}

The $\mu$-APPJ used here is based in principle on dielectric barrier discharge (DBD) operation [12]. It consists of a quartz capillary tube of $1 \mathrm{~mm}$ ID and $3 \mathrm{~mm}$ OD (outer diameter). Two copper electrodes $(50 \mu \mathrm{m}$ in thickness and $10 \mathrm{~mm}$ in width) were wrapped around the capillary glass tube, with a gap of $10 \mathrm{~mm}$ between them. One electrode was powered by ac voltages, while other could be either grounded or left electrically floating. By swapping the position of the driver electrode with the other one, the four possible excitation configurations were tested to find the most intense and longest length of plasma exit plume. The optimum configuration proved to be that with the electrode close to the nozzle of the capillary in a floating configuration with the other one powered. This configuration is similar to a single electrode structure with external ground somewhere outside of the capillary tube [3][5]. Our preliminary observations (not shown) using an ICCD camera to image the plasma confirms that our chosen configuration produces plume lengths (up to $\sim 25 \mathrm{~mm}$ ), similar to the single electrode configuration.

The helium $\mu$-APPJ was excited by $10 \mathrm{kHz}$ ac with voltages between $6 \mathrm{kV}$ and $9 \mathrm{kV}\left(\mathrm{V}_{\mathrm{p}-\mathrm{p}}\right)$. The gas flow rate was controlled by a Rotameter (Omega Engineering) and the highest used was $5.4 \mathrm{slm}$ (standard litres per minute, $\mathrm{L} \cdot \mathrm{min}^{-1}$ ). The highest and lowest exit gas velocities were calculated to be $92.4 \mathrm{~m} \cdot \mathrm{s}^{-1}$ and $4.7 \mathrm{~m} \cdot \mathrm{s}^{-1}$ for flow rates of $4.4 \mathrm{slm}$ and $0.2 \mathrm{slm}$ respectively. These velocities were calculated assuming no leakage in gas handling system and laminar flow of the gas in the system. The cross-sectional profile in the gas velocity across the capillary diameter was not considered in the calculation.

To observe the patterns of perturbation in the neutral gas density as it exits the capillary (flowing helium and its interaction with ambient air) Schlieren imaging was used, with a field of view up to $20 \mathrm{~cm}$. This was done using a z-configuration system [13] with two parabolic mirrors, a continuous xenon arc lamp light source and a conventional camera (Nikon D-80) 
1 as described in previous work [14][15]. The time-resolution of the imaging was a few

2 hundred milliseconds. The plasma plume investigations were carried out by time-averaged and time-resolved images using an ICCD camera (Andor DH520-18F-01). A-50-nanoseconds exposure time was used for imaging the plasma bullet evolution, while a few-milliseconds time resolution was used for viewing the general structure of plasma plume.

To investigate the nature and effectiveness of the $\mu$-APPJ on modifying polymeric surfaces, PS samples (1.2 mm thick, Goodfellow Cambridge Ltd.,) were exposed to the out-flowing plasma for at several nozzle-substrate distances $(10 \mathrm{~mm}, 25 \mathrm{~mm}, 35 \mathrm{~mm}$, and $45 \mathrm{~mm})$ for $60 \mathrm{~s}$. To prepare the samples for this, they were ultrasonically cleaned in isopropanol for $180 \mathrm{~s}$, then rinsed with fresh isopropanol again and dried out under nitrogen flow. The WCA of untreated PS was around $90^{\circ}$ which indicates the hydrophobic characteristic of the PS surface. The WCAs of sessile-water drop $(\sim 0.2 \mu \mathrm{L})$ were measured by CAM100 (KSV Instruments), along a line from the centre of the sample every 2-mm up to a distance of $12 \mathrm{~mm}$.

\section{Results and Discussion}

Figures 1(a) and 1(b) show the Schlieren images for gas outflow with and without plasma struck. The helium flow rate was $4.4 \mathrm{slm}$. We can distinguish in both images regions of laminar and free turbulent flow as marked in the figures. The laminar region is a region of order unidirectional flow, seen as the dark area outside the capillary in Figs 1(a) and 1(b). Outside this, turbulent flow is characterised by the formation of eddies and vortices. Without the plasma jet operating the laminar flow region is measured to be $35 \mathrm{~mm}$ in length, however this shortens to $21 \mathrm{~mm}$ when the plasma is struck. This change in length indicates there must be some interaction between the charge species created in the jet and the neutral gas flow. In the capillary the plasma itself consists of charged species such as electrons and positive $\mathrm{He}^{+}$ ions, photons, neutrals and $\mathrm{He}$ metastables. Outside the capillary, the interaction of the excited plasma with air will lead to the creation of new ionic and exited species, such $\mathrm{O}^{+}$, $\mathrm{OH}^{+}, \mathrm{O}^{-}, \mathrm{O}^{*}, \mathrm{~N}_{2}^{+}[16][17]$. Although the precise plasma-surface interactions are unknown we anticipate that such species as these and also UV and VUV photons in the plasma plume will 
1 cause bond breaking in polymeric surfaces (increased surface energy and subsequent

2 atmospheric oxygen uptake) placed in the flow. This is the rational for choosing these jets as

3 candidates for efficient and cost-effective surface treatment. The contraction in the length of

4 laminar region in the gas flow with plasma operation is interesting and we explore some

5 possible mechanisms for this later.

6 Before this, it is instructive to examine the relationship between the length of the laminar 7 region (determined from Schlieren imaging) and the extent of the visible plasma (from ICCD 8 imaging). These are shown in Fig. 2(a). As the gas flow rate increases from 1 to $5.5 \mathrm{slm}$ the 9 laminar flow region shortens while the length of the visible region increases. As the extent of 10 the visible region exceeds that of the laminar region, the plasma enters a boundary between 11 transitional and turbulent flow and cannot propagate further. At this point the both plasma and laminar gas flow regions then start to decrease with increased gas flow above $4.5 \mathrm{slm}$. With a discharge struck the laminar region is always shorter than in the absence of plasma for all flow rates.

Figures 2(b)-2(e) show the time-averaged 2-D images of the visible plasma for a number of different gas flow rates and nozzle-substrate distances. Clearly, as the flow rate increases the visible plume of the jet at first elongates but then shortens as its tip enters a transition region displaying a slight cork-screw feature at the tip. With further gas flow the tip of plasma becomes turbulent exhibiting a clear cork-screw motion, as shown in Fig. 2(d). The correlation between plasma plume length and gas flow rate is in very good agreement with the reports by Mericam-Bourdet [18] and Karakas [19]. In the Ref. 19 it was established that the helium plasma cannot propagate past the point where the mole fraction of helium in air becomes lower than a critical value. They also discuss the possibility of buoyancy force at work in the outflow when the jet (a $2.5 \mathrm{~cm}$ diameter hollow dielectric tube) is orientated horizontally, particularly when working at a low flow rate. However, we did not observed any associated curvature in the plume with the fine capillary $(0.1 \mathrm{~cm})$ and short jet lengths in this work. In [19], three flow regions for the jet; these are laminar, transition and turbulent regions. In Figs. 2(b) and 2(c) the plasma is in the laminar and transition regions respectively, 
1 and according to the previous report the latter will have a cork-screw type motion at its tip. In

2 Fig. 2(d) the plasma itself is turbulent region with reduced plasma propagation length. In Fig.

3 2(e) the visible jet is terminated at the wall boundary which is $10 \mathrm{~mm}$ from the nozzle and the

4 radial extension of the bullets (visible plume) is about $1 \mathrm{~mm}$, so when the visible plasma is in

5 contact with the surface the contact area is small as seen in the 2-D ICCD plasma glow

6 images. This visible scale on the barrier can be used to compare scale lengths in the Schlieren

7 images and results of radial scans of WCA in last part of this paper.

As described in Ref. 1 the plasma plume is comprised of fast moving discrete regions of

9 ionisation often referred to plasma bullets. This can be seen in our case in Fig. 3 (helium flow

10 rate is $2.9 \mathrm{slm}$ ) where we calculate the fastest bullet speed to be $26 \mathrm{~km} \cdot \mathrm{s}^{-1}$ as it escapes the

11 nozzle. After this, it propagates for few microseconds and then decelerates over the next few

12 hundred ns. These speeds and times are consistent with those obtained in other studies

$13[1][2][19]$. For a flow rate of $2.9 \mathrm{slm}$, the continuous gas speed at exit of the nozzle is

14 estimated to be $62 \mathrm{~m} \cdot \mathrm{s}^{-1}$, that is, some 500 times slower than the maximum bullet speed. The

15 Reynolds number $(R e)$ given as $R e=\frac{V L}{V}$ can be calculated for the system where $V$ is mean

16 fluid velocity, $L$ is the minimum system scale length (nozzle diameter of $1 \mathrm{~mm}$ ), and $v$ is the

17 kinematic viscosity of the fluid $\left(1.22 \times 10^{-4}\right.$ for helium and $1.57 \times 10^{-5} \mathrm{~m}^{2} \cdot \mathrm{s}^{-1}$ for air, both at

$18300 \mathrm{~K})$. The calculated value of $R e$ for $\mathrm{He}$ is $\sim 500$ which indicates a laminar flow regime and

$19 \sim 3900$ for air which is the transition regime, the boundary between laminar and turbulent

20 flow [20].

21 To understand the contraction of the laminar region and earlier onset of turbulence with the plasma struck we consider two possible mechanisms. These are 1) gas heating through electron collisions and 2) momentum transfer from ions to neutral gas atoms. Through elastic collisions between electrons and neutrals it is possible that the neutral gas is heated, leading to a decrease in the local density and a concomitant increase in the exit flow velocity; The maximum energy transferred in an elastic collision from a plasma electron of mass $\left(m_{\mathrm{e}}\right)$ and 
1 temperature (energy) $T_{\mathrm{e}}$ to a cold neutral helium atom of mass $M_{\mathrm{n}}$ can be stated as $\frac{4 m_{\varepsilon}}{M_{n}} T_{g}$. If

2 the electron-atom collision frequency is $v_{\mathrm{e}-\mathrm{n}}$ then in the life-time $\tau_{\mathrm{e}}$ of an electron in the

3 discharge the total number of energy transferring collisions to the neutrals as a proportional

4 of the total neutral density $N_{\mathrm{n}}$ is $\frac{n_{\mathrm{g}} v_{\xi-\mathrm{n}} \tau_{\bar{z}}}{N_{n}}$, where $n_{\mathrm{e}}$ is electron density. Assuming little cooling

5 of the neutral gas through interaction with the walls, an upper limit on the gas temperature 6 rise $\Delta T_{\mathrm{g}}$ is therefore given by

$$
\Delta T_{g} \sim \frac{4 m_{g}}{M_{n}} T_{g}\left(\frac{n_{g} v_{g-n} r_{g}}{N_{n}}\right)
$$

8 In these types of discharge we have typically, $n_{\mathrm{e}}=10^{18}-10^{20} \mathrm{~m}^{-3}[21][22]$, and $T_{\mathrm{e}}=1-2 \mathrm{eV}$ 9 [2][21][22] with $M_{\mathrm{n}}=6.698 \times 10^{-24} \mathrm{~g}$ and $m_{\mathrm{e}}=9.110 \times 10^{-28} \mathrm{~g}$. To find the electron life time $\tau_{\mathrm{e}}$ 10 we consider the plasma to be collision-dominated with diffusional processes across the radius of the plasma setting the lifetime. For an electron diffusion coefficient of $D_{\mathrm{e}}$ and a plasma radius $L, \tau_{\mathrm{e}}$ is given by Eq. (2)

$$
\tau_{g}=\frac{L^{2}}{D_{g}},
$$

where in our case we take $L$ (half width of the capillary) $=0.5 \mathrm{~mm} . D_{\mathrm{e}}$ is given in [23] as .

$$
D_{\theta}=\frac{k T_{Q}}{\theta} \mu_{\varepsilon}=\frac{k T_{\varepsilon}}{m} \frac{\theta}{m v_{\varepsilon-n}}
$$

16 Here $\mu_{\mathrm{e}}$ is the mobility. From paper [23] we have $v_{\mathrm{e}-\mathrm{n}}=10^{12} \mathrm{~s}^{-1}$ and we calculate $D_{\mathrm{e}} \sim 0.12$ $17 \mathrm{~m}^{2} \mathrm{~s}^{-1}$, giving $\tau_{\mathrm{e}}$ as $2.1 \times 10^{-6} \mathrm{~s}$. This gives from Eq. (1) a maximum value of $\Delta T_{\mathrm{g}}$ of about $35 \mathrm{~K}$ 18 with the maximum $n_{\mathrm{e}}\left(=10^{20} \mathrm{~m}^{-3}\right)$ and $T_{\mathrm{e}}(=2 \mathrm{eV})$ quoted above. Previous experimental and 19 simulation studies have shown typical gas temperatures 20-120 K above ambient 20 [24][25][26]. Our simple calculations are in general agreement with this. Here, our upper 21 limit figure represents about a 30\% increase in gas temperature above ambient due to electron 22 heating, however the associated reduction in local number density and increase is exit gas velocity assuming continuity of flow seems unlikely to account for the total reduction in the extension of the laminar region of $\sim 30 \%$ as seen in figure 1. According to Fig. 2(a) this 
1 would require an increase in gas velocity of about $30 \%$. The increase in gas velocity

2 calculated above provides the same increase in Reynolds number for He, but still indicates 3 laminar flow.

4 Another mechanism that may account for the reduction in the length of the laminar region, 5 is momentum transfer from positive ions (in the plasma bullet) to the neutral gas atoms, 6 increasing the gas fluid exit speed. This process may be important when the driven electrode 7 is positive causing ion motion along the direction of the gas stream, however, it does require 8 positive ions to preferentially drift in one direction over a number of voltage cycles as 9 observed with displaced electrodes on DBD plasma actuators[23][27].

10 In an electric fields $E$ the drift velocity of the ion $v_{\mathrm{i}}$ (assumed to be mobility dominated in 11 the collisional plasma) is given by $v_{\mathrm{i}}=\mu_{\mathrm{i}} E$, where $\mu_{\mathrm{i}}$ is the coefficient of mobility. In our 12 system $E$ has a maximum value of 6 (or 9) $\mathrm{kVcm}^{-1}$ (i.e. $6 \mathrm{kV}$ drop between electrode 13 separated by $1 \mathrm{~cm}$ ). In this regime, at atmospheric pressure, the ion mobility is given as $\mu_{i}=\frac{8 \times 10^{-3}}{p}\left(1-8 \times 10^{-3} E / p\right) \mathrm{cm}^{2} \mathrm{~V}^{-1} \mathrm{~s}^{-1}$ for $E / p<25 \mathrm{Vcm}^{-1}$ torr $^{-1}$ [23]. In our case, this gives $\mu_{\mathrm{i}}=7.89$ (or 9.53) $\mathrm{cm}^{2} \mathrm{~V}^{-1} \mathrm{~s}^{-1}$ and ion drift speeds of 592 (or 858) $\mathrm{ms}^{-1}$. The momentum exchange $(\Delta M)$ and hence the velocity increase of the neutral fluid $\Delta v_{\mathrm{g}}$ produced through collisions with the drifting ions of density $n_{\mathrm{i}}\left(=n_{\mathrm{e}}\right)$ can be readily estimated. Equating the momentum change in the gas occurring over the lifetime of the bullet between electrodes and the rate at which ions lose momentum through collisions we can write $M_{g} \Delta v_{g} N_{g} \frac{1}{\tau}=M_{i} v_{i} n_{i} v_{i-n}$, where $v_{\mathrm{i}-\mathrm{n}}\left(\sim 10^{11} \mathrm{~s}^{-1}\right)$ [23] is the ion-neutral collision frequency and $\tau\left(\sim 10^{-7} \mathrm{~s}\right)$ is the total time of the interaction (= time for the bullet to pass between electrodes). From this, we calculate $\Delta v_{\mathrm{g}}=24$ (or 36) $\mathrm{ms}^{-1}$. This is clearly a sizable increase on the unperturbed velocity and may affect the exit gas conditions and on-set of turbulence. Interestingly, it is constituent, although slightly higher, than the typical ion wind speeds produced by DBD plasma actuators [23][27]. Although we predict ion velocities in the capillary of 592 (or 858) $\mathrm{ms}^{-1}$ during the maxima in the electric field, outside the capillary, in 
1 the output plume it has been shown that there is little or no translational velocity in the ionic

2 component. For instance, laser-induced fluorescence signals from $\mathrm{N}_{2}{ }^{+}$ions where found not 3 be Doppler shifted [28]. It may be the case that efficient coupling of the He ions to the neutral 4 fluid in the capillary produces only slow ions by the time they reach atexit of the nozzle and 5 no further energy exchange with atmospheric species such $\mathrm{N}_{2}$ in regions where the $E$-field is 6 negligible (outside the jet) is possible. Clearly, for the above mechanism of ion-gas coupling 7 to work, it is necessary that there is a preferential ion drift in the direction of the gas flow. 8 During a full period in voltage both upstream and downstream bullets can be observed (i.e. on the negative and positive parts of the voltage waveform), however the downstream bullets (in the direction of the flow) are always brighter with higher associated measured current. If these bullets have higher charged particle densities as indicated by the higher currents and more intense optical output then such a preferential ion flow may occur.

As mentioned above, the lateral scale of visible plasma plume reduces when the plume strikes a barrier surface. However, Schlieren image in Fig. 4(a) shows no free turbulence as we shall see the surrounding neutral gas is highly turbulent (wall turbulence) in this case for substrate at $10 \mathrm{~mm}$ from the nozzle. The other Schlieren images in Figs. 4(b) and 4(c) show also large area interactions of the neutral gas with the substrate for a range of gas flow rates for nozzle-substrate distances of $25 \mathrm{~mm}$ and $45 \mathrm{~mm}$. It can be seen clearly in Fig. 4(c) that after the laminar region, the gas expands at angles approaching 45 degrees. This is similar to the free stream case in Fig 1 with no substrate. With substrate barriers placed in the outflow, strong wall turbulence covers the entire surface up to $30 \mathrm{~mm}$ from the gas strike point and even extends around the substrate. The extension of the change of the PS surface WCA is also shown in Fig. 4, denoted by the white extension bar, and we see that it is smaller than the region of wall turbulence. This shows the effect of the interaction of the visible plasma and excited gas on the surface properties of polymeric substrates.

The influence of the plasma plume on the substrate was studied from the point of view of the area over which surface modification (changing of the surface wetting from hydrophobic to more hydrophilic) can take place. The results are shown in Fig. 5 where it can be seen that 
1 the treatment widths (the full width over which the WCA angles changes from hydrophobic $290^{\circ}$ to hydrophilic $40^{\circ}$ ) are between $22 \mathrm{~mm}$ and $12 \mathrm{~mm}$ (inset Fig. 4) which is substantially

3 larger than the width of the visible glow but smaller than area of the wall turbulence. The operating parameters (power, flow rate, nozzle-substrate distance) chosen here to conduct the WCA measurements are similar to those in our previous work with single $\mu$ APPJs [8][9], and the surface modification results are consistent between studies. With samples at distances of 35 and $45 \mathrm{~mm}$ from the nozzle, the visible plasma plume does not strike the surface, however the change in WCA is markedly different. Going from 35 to 45 seems to change the surface conditions. Excited radicals which may be responsible for some of the surface treatment may not be able to extend past much $35 \mathrm{~mm}$. In Ref. 9 we conjecture that surface treatment at large distances from the visible plume may be due to an inner core of VUV photons surrounded by a envelop of radicals. The emitted photons form the glows can be transported down the helium column to the PS surface so avoiding absorption by oxygen molecules in ambient air. This outer envelope may decay with distance, particularly if the gas is turbulent and there is strong mixing with ambient air. When the visible plasma is in contact with the surface ionic species inside the plasma bullet [29] may take part in the surface modification. The radial dependency of WCA and effective treatment widths are shown in Fig. 5(b) as function of nozzle-substrate distance. The width of the treated area was $22 \mathrm{~mm}$ for a $10 \mathrm{~mm}$ nozzle-substrate distance, however this reduced to $13 \mathrm{~mm}$ as the substrate was moved to a distance of $45 \mathrm{~mm}$ from the source. These trends are consistent with our simple picture described above of the active species in the exit plume and also with the results of Szili et al [8] who show the same trends of narrowing treatment area with increasing nozzlesubstrate distances.

\section{Conclusions}

2-D optical imaging and Schlieren photography have been used to study the out flow of a $\mu$ APPJ and the interaction of the plasma and gas with a substrate. We have shown that helium outflow changes from laminar to turbulent conditions at distances of between 20 and $50 \mathrm{~mm}$. 
1 Without the plasma operating, (and for flow rates above $1.4 \mathrm{slm}$ ), the extension of laminar

2 region decreases with increasing flow rate. This length decreases by typically 10 to $30 \%$

3 when the plasma is struck. We have explored two possible mechanisms for this effect and a

4 combination of gas heating through elastic electron collisions and also ion momentum

5 transfer to the neutral gas causing higher exit gas velocities may be responsible for the

6 quicker onsets of turbulence. The extension of the visible jet (composed of plasma bullets)

7 increases with flow rate but remains less than the extension of the laminar flow. The visible

8 plasma cannot be conducted past the point where gas turbulence begins.

9 The effects of the $\mu$-APPJ on the wettability and modification of a polystyrene surface was

10 also studied. The treated surface changed from hydrophobic to hydrophilic after exposure to

11 the $\mu$-APPJ and this change of WCA $\left(50-60^{\circ}\right)$ was observed for 10,25 , and 45 mm capillary-

12 PS distances when the jet had a visible (plasma) extension of $25 \mathrm{~mm}$ and a laminar region of

13 flow of $\sim 40 \mathrm{~mm}$ length. For source-substrate distances greater than $45 \mathrm{~mm}$ the change in

14 WCA suddenly dropped to $\sim 10^{\circ}$. Furthermore, the treated area of the PS decreased with

15 increasing distance between the nozzle and PS surface.

16

17 Acknowledgement

18 This work was supported by Engineering and Physical Sciences Research Council (EPSRC

19 Grant Reference: EP/G048444/1).

20 
3 FIG. 1 Schlieren photographs showing laminar and turbulent flows (a) without plasma and

4 (b) with plasma. High gas flow rate of helium was supplied at $\sim 4.4 \mathrm{slm}$ for both. Plasma was 5 operated at $10 \mathrm{kHz}$ ac while the voltage was fixed at $8 \mathrm{kV}_{\mathrm{p}-\mathrm{p}}$ for case (b).

6

7 FIG. 2 Shows (a) various lengths of laminar flows (Schlieren) and ICCD plasma plume 8 results against various gas flow rates, (b) turbulent jet with high gas flow rate of $3.6 \mathrm{slm}$, 9 plasma light strike on the surface (c) for a flow rate of $4.4 \mathrm{slm}$ and excited plasma with 10 reduced plume length (d) for $5.4 \mathrm{slm}$. A closed glass barrier at a distance of $10 \mathrm{~mm}$ for (e) 11 with a $4.4 \mathrm{slm}$. This clearly shows a strong emission on the surface but still has a small 12 diameter around $1 \mathrm{~mm}$.

14 FIG. 3 Spatiotemporal behaviours of the plasma bullets were observed by ICCD camera with $1550 \mathrm{~ns}$ time resolution. Helium gas flow rate of $2.9 \mathrm{slm}$ was used in this case. The triggered 16 time and a 10-mm scale bar are displayed inset.

18 FIG. 4 Schlieren photographs show wall turbulence on the glass barrier surface. The barrier 19 is separated with different distances, (a) $10 \mathrm{~mm}$, (b) $25 \mathrm{~mm}$, and (c) $45 \mathrm{~mm}$, with treated 20 width (FWHM) of PS inset. Helium APPJ operated at $8 \mathrm{kV}_{\mathrm{p}-\mathrm{p}}$ and $10 \mathrm{kHz}$, when the gas flow 21 rate was fixed at $4.4 \mathrm{slm}$.

23 FIG. 5 (a) shows WCA radial scan of PS for several nozzle-substrate distances 10, 25, 35, 24 and $45 \mathrm{~mm}$. (b) shows an estimated values of the effective treated width. 


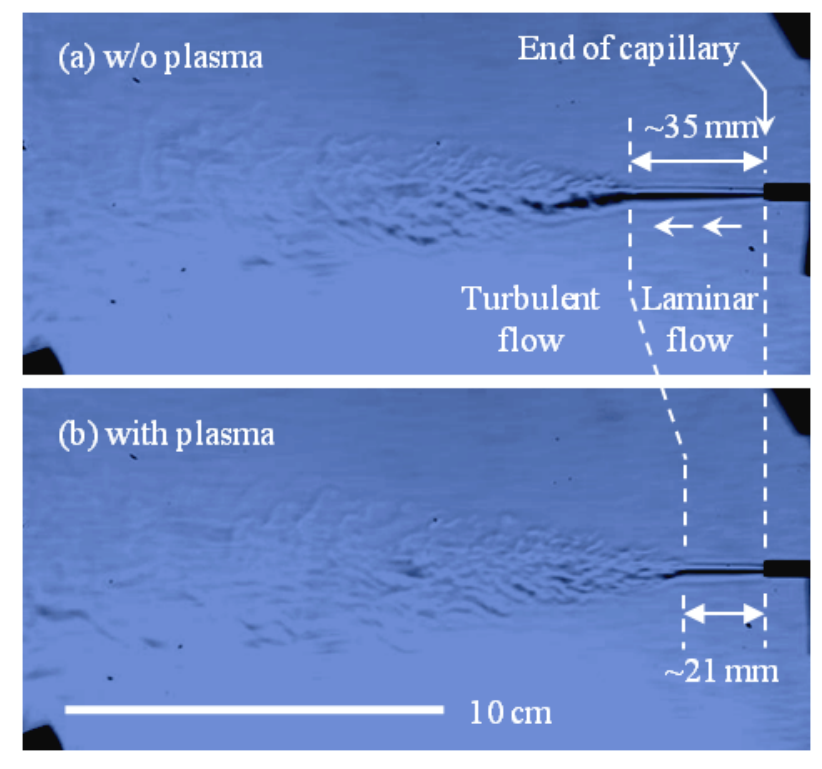

FIG. 1

3 

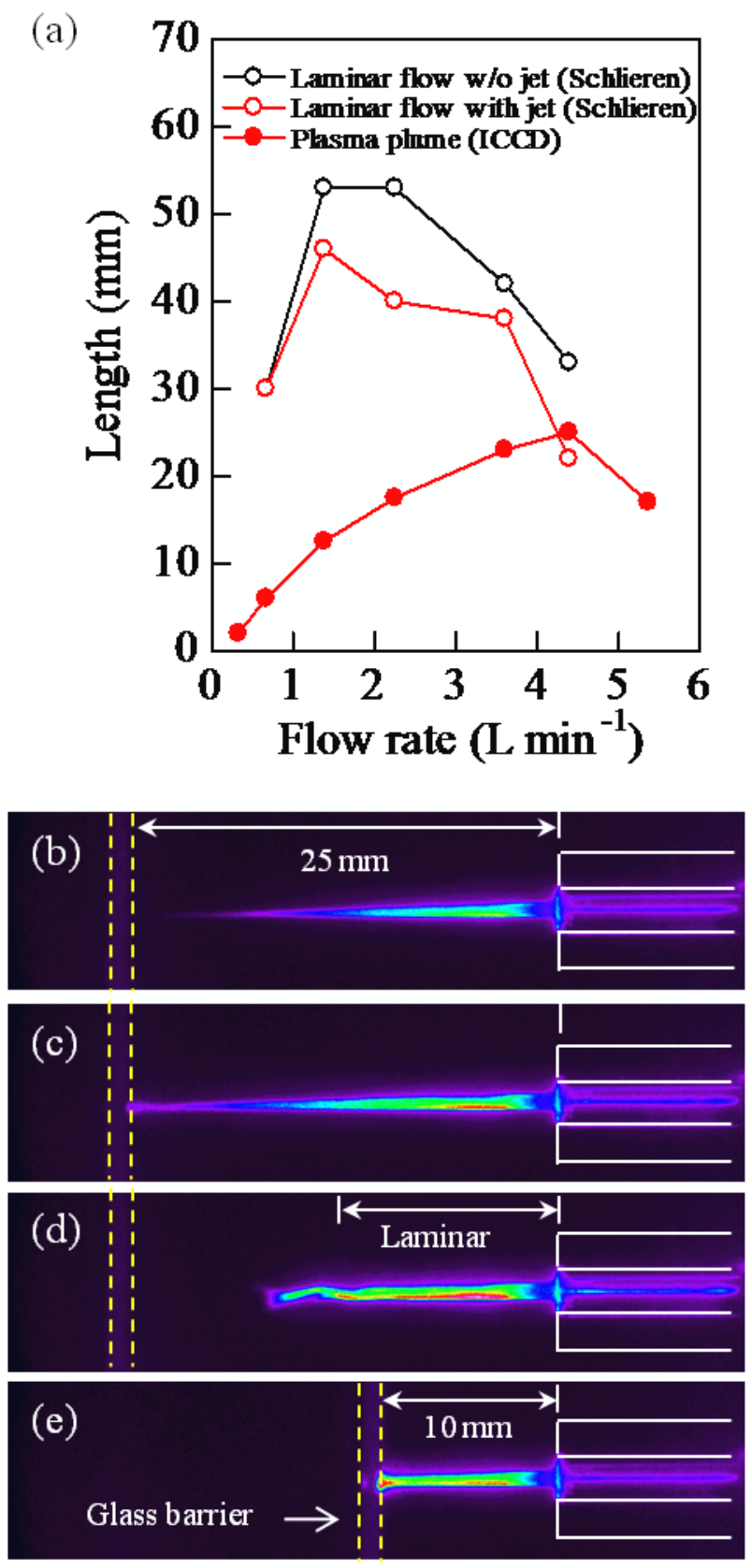

Emission intensity (a.u.)

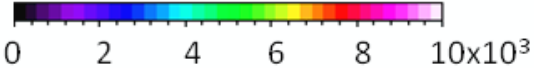

FIG. 2 
Emission intensity (a.u.)
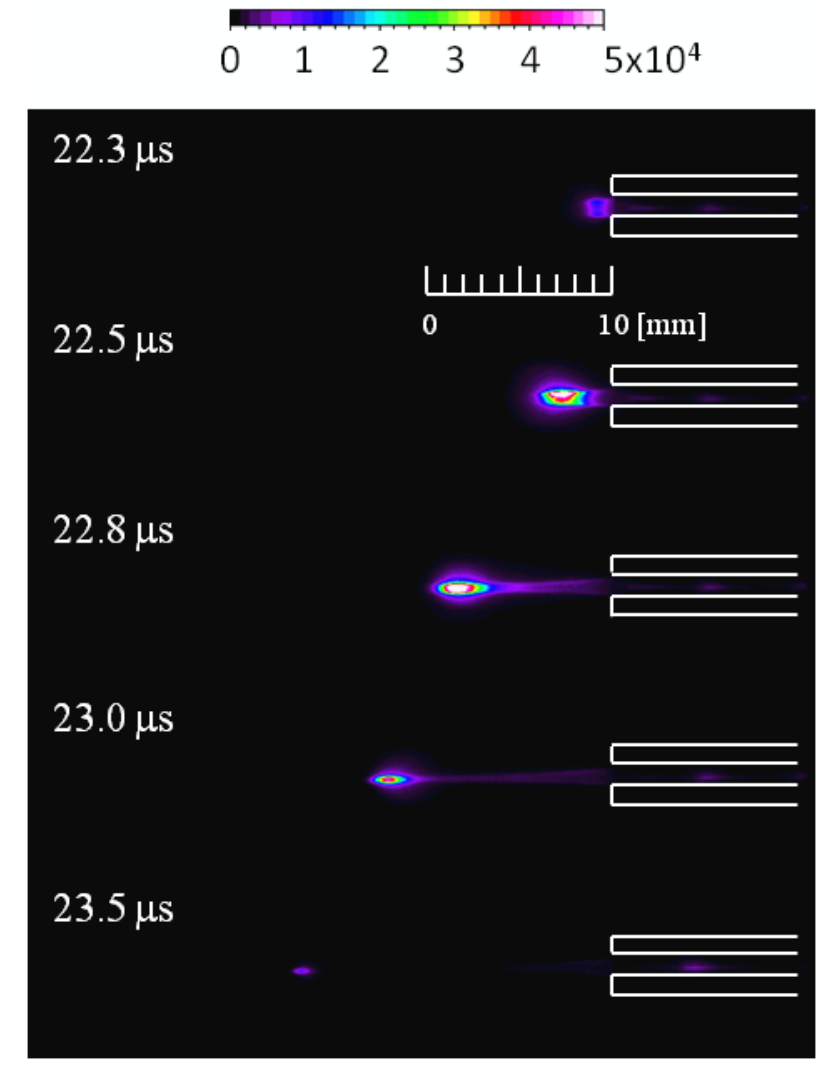

FIG. 3

3 


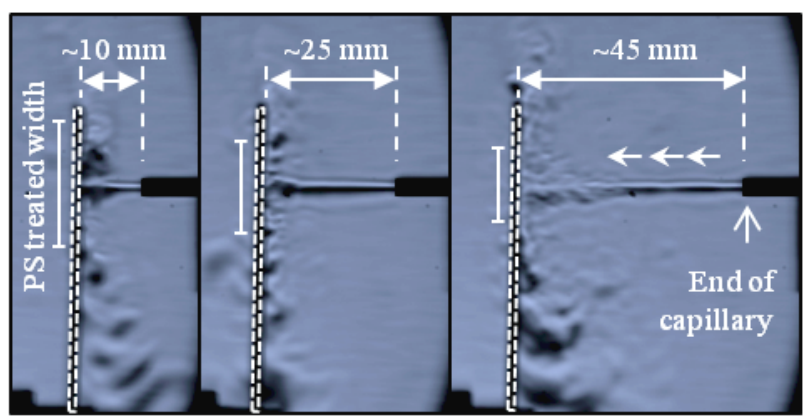

(a)

(b)

(c)

FIG. 4 

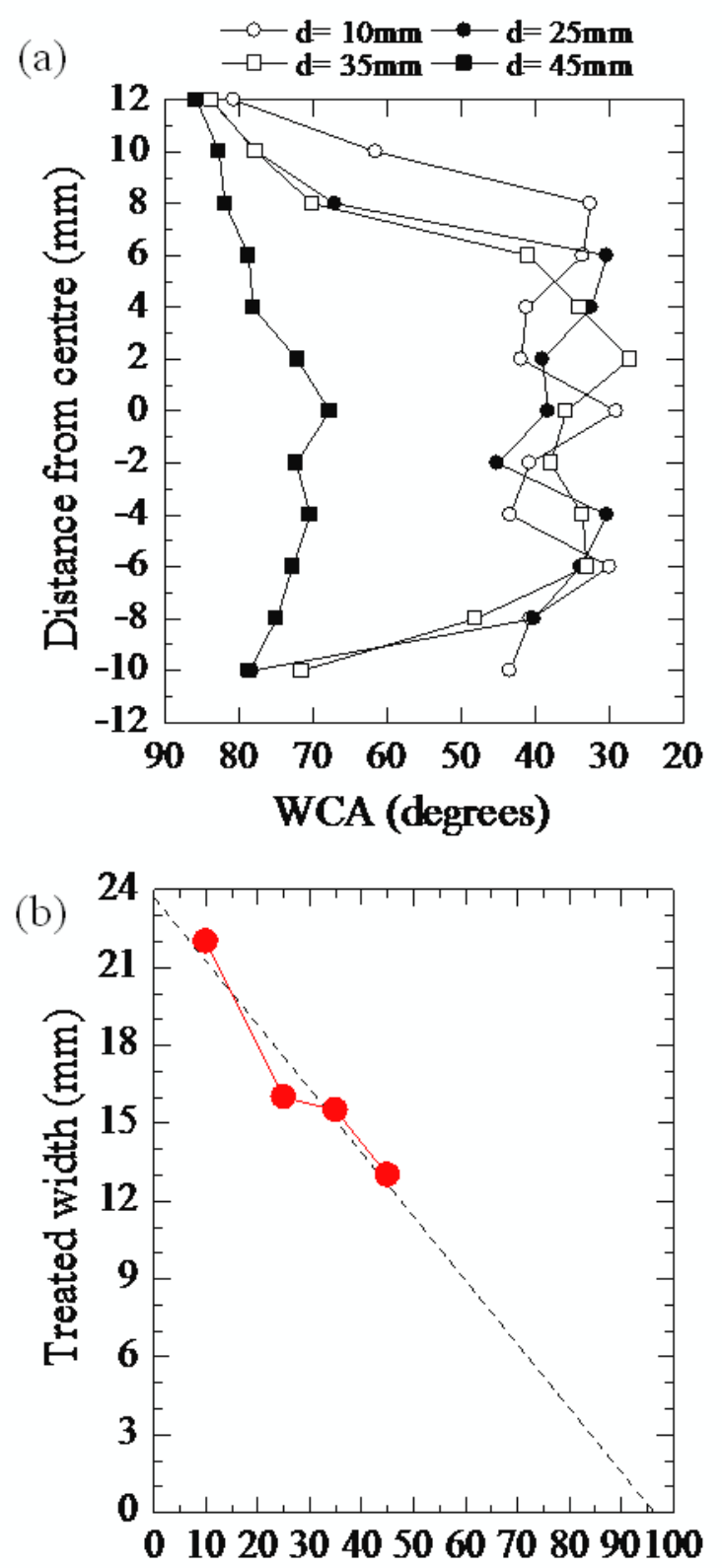

Capillary-PS distance (mm)

FIG. 5 


\section{$1 \quad$ References}

[1] Teschke M, Kedzierski J, Finantu-Dinu E G, Korzec D and Engemann J 2005 IEEE Tran. on Plasma Sci. 33, 310

[2] Tachibana K 2006 IEEJ Trans. 1 pp.145-155

[3] Walsh J L, Shi J J and Kong M G 2006 Appl. Phys. Lett. 88171501

[4] Iza F, Kim G J, Lee S M, Lee J K, Walsh J L, Zhang Y T and Kong M G 2008 Plasma Processes and Polymers 5322

[5] Ikawa S, Kitano K, Hamaguchi S 2010 Plasma Processes and Polymers 733

[6] Lu X, Jiang Z, Xiong Q, Tang Z, Hu X and Pan Y 2008 Appl. Phys. Lett. 92081502

[7] Ito Y, Urabe K, Takano N and Tachibana K 2008 Appl. Phys. Express 1067009

[8] Szili E J, Al-Baraineh S A, Bryant P M, Short R D, Bradley J W and Steele D A 2011 Plasmas Processes and Polymers 8 pp. 38-50

[9] Oh J-S, Bradley J W, Doherty K G, Sheridan C M, Williams R L, Bowfield A, Unsworth P, and Weightman P 2010 Proceedings of AVS 57 Int. Sym. \& Exhibition p.33

[10] Lee K, Paek K-H, Ju W-T and Y. Lee 2006 Journal of Microbiology 44 pp.269-275

[11] Fridman G, Friedman G, Gutsol A, Shekhter A B, Vasilets V N and Fridman A 2008 Plasma Processes and Polymers 5 pp.503-533

[12] Koinuma H, Ohkubo H, Hashimoto T, Inomata K and Shiraishi T 1992 Appl. Phys. Lett. 60816

[13] Merzkirch W 1987 Flow visualization Academic Press, Inc. (chapter 3)

[14] Kontis K, An R, Zare-Behtash H and Kounadis D 2008 Physics of Fluids 20016104 [15] Zare-Behtash H, Kontis K, Gongora-Orozco N and Takayama K 2009 Int. J. of Heat and Fluid Flow 30 pp. 561-576

[16] Stoffels E, Aranda-Gonzalvo Y, Whitmore T D, Seymour D L and Rees J A 2007 Plasma Sources Sci. Technol. 16549.

[17] Urabe K, Morita T, Tachibana K, and Ganguly B N 2010 Journal of Physics D: Applied Physics, 43095201. 
[18] Mericam-Bourdet N, Laroussi M, Begum A and Karakas E 2009 Journal of Physics D: Applied Physics, 42055207

[19] Karakas E, Koklu M and Laroussi M 2010 Journal of Physics D: Applied Physics, 43 155202

[20] Hinze O J 1959 Turbulence McGraw-Hill

[21] Park J, Henins I, Herrmann H W, Selwyn G S, Jeong J Y, Hicks R F, Shim D and Chang C S 2000 Appl. Phys. Lett. 76288

[22] Schaper L, Reuter S, Waskoenig J, Niemi K, Schulz-von der Gathen V and Gans T 2009 Journal of Physics: Conference Series 162012013

[23] Jayaraman B, Cho Y-C and Shyy W 2008 Journal of Applied Physics 103053304

[24] Bibinov N K, Fateev A A and Wiesemann K 2001 Journal of Physics D: Applied Physics 341819

[25] Kang W S, Kim H-S and Hong S H 2010 IEEE Trans. on Plasma Sci. 381982

[26] Jidenko N, Bourgeois E and Borra J-P 2010 Journal of Physics D: Applied Physics 43 295203

[27] Likhanskii A V, Shneider M N, Macheret S O and Miles R B 2008 Journal of Applied Physics 103053305

[28] Urabe K, Ito Y, Tachbana K and Ganguly B N 2008 Appl. Phys. Express 1066004 [29] Oh J-S, Aranda-Gonzalvo Y and Bradley J W to be submitted 